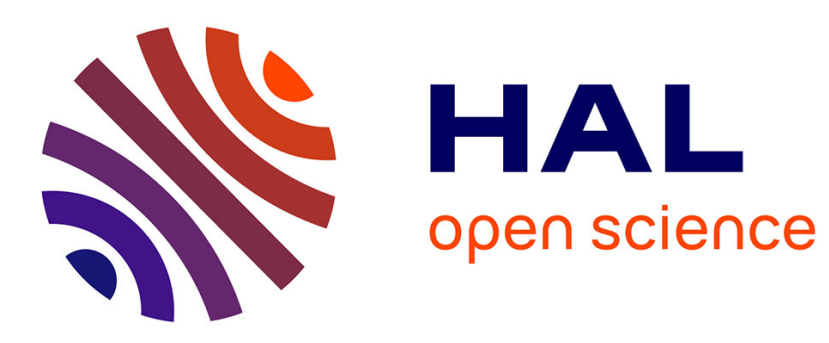

\title{
A design approach for safety based on Product-Service Systems and Function-Behavior-Structure
}

Leyla Sadeghi, Jean-Yves Dantan, Luc Mathieu, Ali Siadat, Mohammadmohsen Aghelinejad

\section{- To cite this version:}

Leyla Sadeghi, Jean-Yves Dantan, Luc Mathieu, Ali Siadat, Mohammadmohsen Aghelinejad. A design approach for safety based on Product-Service Systems and Function-Behavior-Structure. CIRP Journal of Manufacturing Science and Technology, 2017, 19, pp.44-56. 10.1016/j.cirpj.2017.05.001 . hal-02337367

\section{HAL Id: hal-02337367 \\ https://hal.science/hal-02337367}

Submitted on 29 Oct 2019

HAL is a multi-disciplinary open access archive for the deposit and dissemination of scientific research documents, whether they are published or not. The documents may come from teaching and research institutions in France or abroad, or from public or private research centers.
L'archive ouverte pluridisciplinaire HAL, est destinée au dépôt et à la diffusion de documents scientifiques de niveau recherche, publiés ou non, émanant des établissements d'enseignement et de recherche français ou étrangers, des laboratoires publics ou privés. 


\section{A Design Approach for Safety Based on Product-Service Systems and}

\section{Function-Behavior-Structure}

Leyla SADEGHIa, Jean-Yves DANTANª, Luc MATHIEU ${ }^{b}$, Ali SIADATa, Mohammad Mohsen AGHELINEJAD ${ }^{a}$

a Arts et Métiers ParisTech, HESAM, Université de Lorraine, LCFC, F-57000 Metz, France

b École normale supérieure Paris-Saclay, LURPA, F-94235 Cachan, France

Abstract: Design for human safety is a complex issue because of the variability of human activities, machines and their environment as well as the variability of possible interactions between these components. The working situation is comprised of the means and the person(s) who act to carry out task(s) in a working environment in accordance with the conditions set for carrying out the task(s). The working situation can generate the hazardous conditions and undesirables events lead to harm. This paper deals with the working situation identifying and analyzing during design to improve safety. ProductService System (PSS), which is an integrated combination of products and services that shift from product and service systems to product-service systems has been used. The Function-Behavior-Structure (FBS), which covers behavior, is considered to include product and its utilization. The interaction between PSS and FBS, proposed in present paper, allows considering product behaviors and its interaction with service activities. This paper proposes a modelling of the transitions between FBS and PSS paradigm to distinguish the realization of functions by a product part, a service part or a combination of both. The analysis of this interaction is helpful for working situation analysis. Product and service behaviors modelling also are proposed in order to help this analysis. The applicability of the proposed approach is demonstrated through the application to the Power Take-Off (PTO) drive shaft.

Keywords: design for human safety, working situation, product-service system, function-behavior-structure 


\section{Introduction}

The main responsibility of making a machine safe lies in the design process (Caputo et al. 2013). In this context, the term "Design for Safety" (DfS) captures this effort to integrate the knowledge on safety in the design process (Sadeghi et al. 2013).

The reviewing of the literature shows most of the publications on this subject have offered solutions that can be intervene quite late in the design process, often only on the detailed design phase, when significant decisions about product principles and structures have been taken. The most of methods that are used early in the design process, generally set constraints and are used to verify and validate. It should be highlighted the work conducted by Ghemraoui and her colleagues (Ghemraoui et al. 2009; Sadeghi et al. 2013). Their proposition consists in a general suggestion for systematic risk identification and human-safety integration in the early design phase. The reviewing of the literature shows that use conditions are not or poorly taken into account during the design phase (Houssin et al. 2006) and there are always a gap between what is imagined in design and what is lived during the product utilization. Indeed, one of the most important sources of risk is linked to variety in working situation. To take into account this variety, idea is designing human behaviors performed in working situation in parallel with products, neither designing only products nor designing human activities.

These results demonstrate the growing importance of considering working situation as a core element of design for human safety (DfHS). The question then arises is: How to integrate working situation into design process? As mentioned previously, one of the most important sources of risk is linked to a divergence between expected working and real working. This demonstrates that the all the activities related to utilization of a system should be considered during design. The working situation identifying and analysis during design process allow overcoming this problem. Thus, it becomes more a question of How to identify and analysis working situation during 
design process? Whereas, the behavior describes how the system and its components perform (Kannengiesser \& Gero 2011), so this concept should be considered for working situation analysis. Indeed, behavior refers to process or activity to be performed by product or human. So, we need a design theory which covers this concept. Thus, the question to be answered is How to model the behaviors?

The remainder of this paper is organized as follows. In Section 2, terms related to DfHS and their definitions have been presented. This section, after description of a literature review on DfHS, presents the research objectives of present study. Section 3 explains the proposed approach to integrate safety in the earliest design phases. In this section, working situation identifying and analysis have been described. In order to help this analysis, behaviors modelling are proposed. It helps decision making for selecting safer product behavior during design process. The effectiveness of the proposed approach is demonstrated in Section 4 by applying it to a power take-off (PTO) drive shaft. Finally, the conclusions are defined in Section 5.

\section{Research background and objective}

\subsection{Terms related to DfHS and their definitions}

Human safety concerns accident prevention in work situations (Sadeghi et al. 2015). Work situation is comprised of the means and the person(s) who act to carry out task(s) in a working environment in accordance with the conditions set for carrying out the task(s). Service is described through the concept of activity. Regarding this any user activity performed in working situation then considered as a service. In our context, service could be defined as the utilization characteristics of user's product and all the activities related to this utilization. This concept includes addressing user's safety in working situation. Product is physical artefact to satisfy users' needs. System includes 
product and service. The work situation impacts on the human safety who works with/ on/ around of system which may contain hazard. If there is no hazard, there is no possibility of a hazardous situation and no possibility of presence of a danger for the system.

A hazardous situation exists when one or more persons are exposed to a hazard. If there is a hazard, a hazardous situation is possible. If there is no hazardous situation, there is no possibility of presence of a danger for the system. If there is a hazardous situation, we consider that the accident is always probable. In this case, a hazardous event is possible and there is possibility of presence of a danger for the system. Harm occurs as a result of a hazardous event. Risk is defined as an estimate of the probability of occurrence of this harm and its severity that could result. Probability is defined as an estimate of the probability of a hazardous situation occurring (exposure) and the probability of a hazardous situation leading to harm. Severity is defined as an estimate of the magnitude of harm. In producing the measure that becomes a statement of risk, it is necessary that determinations be made for the: existence of a hazard(s), exposure to the hazard, frequency of endangerment of that which is exposed to the hazard, severity of the consequences should the hazard be realized (the extent of harm or damage to people, property, or the environment) and probability of the hazard being realized. This risk which must avoided, eliminated, or controlled in the design and redesign processes of system which will result in improvement in the safety of human at work situation. This has been represented in Figure 1.

As mentioned previously, the aim of the research presented in this paper has been to identify and analysis the working situation. For this aim, all the activities related to utilization of system should be considered during design. This aspect illustrates that the 
system functions and service activities should be integrated seamlessly from the early design phases.

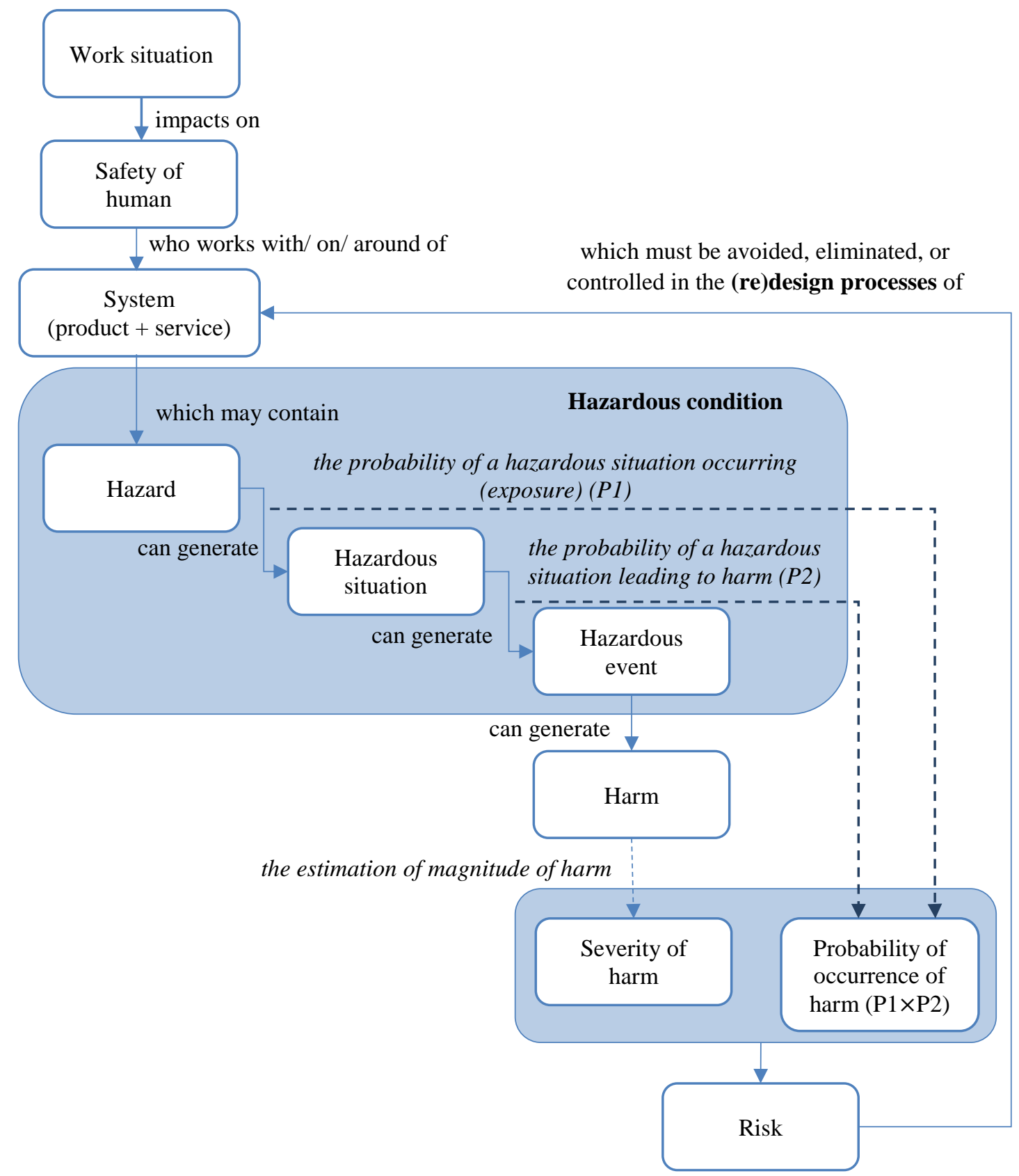

Figure 1. Terms related to DfHS

Service part is described through the concept of activity. Regarding this any user activity performed in working situation then considered as a service. In our context, service could be defined as the utilization characteristics of user's product and all the activities related to this utilization. This concept includes addressing user's safety in 
working situation. The working situation analyzing allows formalizing this concept in the DfHS context with associating utilization and human activities.

Current industrial problems mainly concern the environment and the impact of mass production/consumption of artefacts (Tomiyama 1997; Umeda et al. 2000). One of the identified solutions is the concept of Product-Service Systems (PSS). A PSS is an integrated combination of products and services that shift from product and service systems to product-service systems. The PSS is used in a broader sense, as a model to represent the defined "operating system" composed of interdependent product parts.

The concepts of product, service, system and working situation are redefined in the context of this research as:

- Product: physical artefact to satisfy users' needs;

- Service: utilization characteristics of user's product and all the activities related to this utilization;

- System: product +service;

- Working situation: is comprised of the means and the person(s) who act to carry out $\operatorname{task}(\mathrm{s})$ in a working environment in accordance with the conditions set for carrying out the task(s).

Let us take power take-off (PTO) drive shaft, a means for transmitting rotary power from the tractor to the implement, as an example (Figure 2). In PTO drive shaft, the movable shaft disengages from kinetic energy. Service is related to one or more activities which done by person on or around of PTO drive shaft. Whole of PTO drive shaft and the activity done by person near it constitute the system. When the PTO drive shaft is operating with missed, broken, damaged or poorly fitting safeguards and a person gets close to the PTO drive shaft, there is a potential "entanglement hazard". The operator may be in the vicinity of the source of kinetic energy. This system therefore presents a 
hazardous situation. A human may contact the source of kinetic energy. The PTO drive shaft therefore has a dangerous event.

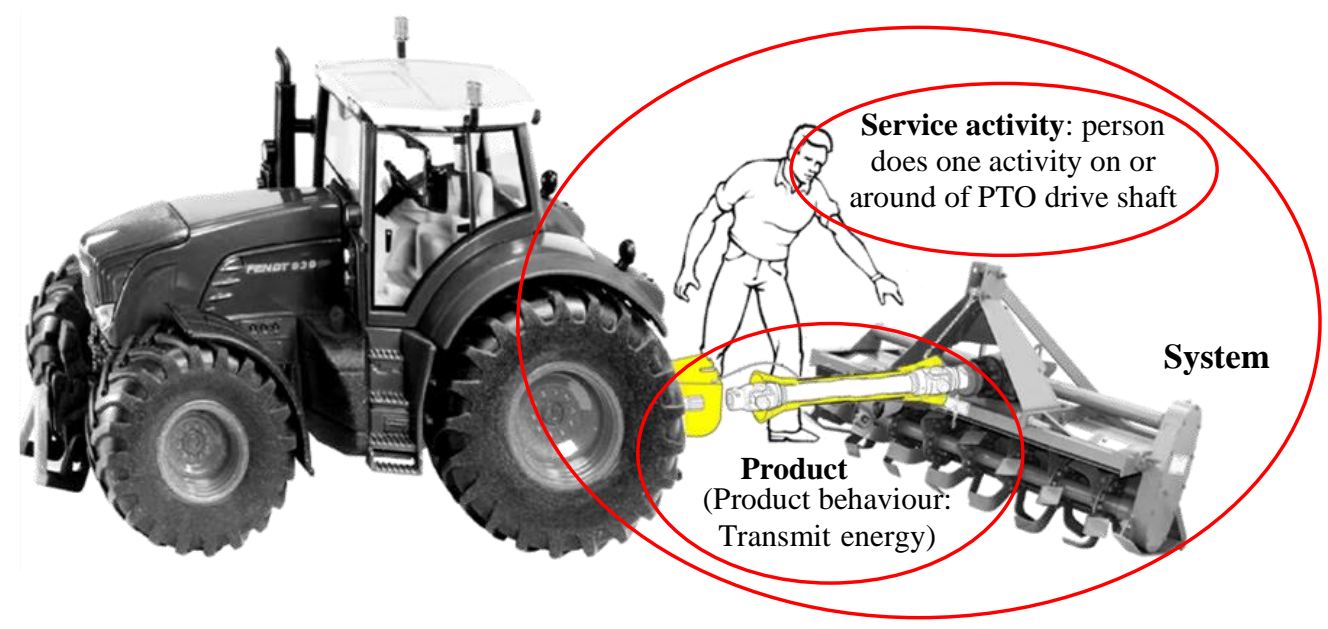

Figure 2. PTO drive shaft accident analysis

\subsection{Literature review on applications of DTM and DTT to analyze and identify work situations in DfHS}

To improve human safety during design process, the large number of studies covering a wide variety of topics (e.g., Gauthier and Charron 2002; Houssin and Coulibaly 2011; Marsot and Claudon 2004; Houssin et al. 2006; Duijne et al. 2007; Ghemraoui, Mathieu, and Tricot 2009a, 2009b; Sadeghi et al. 2013a, 2013b, 2015) have been developed. Recently, Sadeghi et al. (2016) provided a detailed analysis of the literature in order to identify literature trends and emerging research topics in DfHS. Figure 3 shows the framework of DfHS. Risk and work situation are two aspects which must be considered for human safety. Applying design theories and methodologies (DTM) and design tools and techniques (DTT) help to integrate safety in design process. For more information on different DTM and/or DTT, the reader can refer to (Andreasen 2011; Kroll 2013; Lutters et al. 2014; Le Masson, Dorst, and Subrahmanian 2013; Tomiyama et al. 2009). These papers classified or provided an overview of DTM and/or DTT. 
The general principles of risk prevention in the work situation can be found through DTT. They focused in particular on the applications of DTM and DTT to analyze and identify work situations in order to improve human safety in manufacturing system design. Table 1 summarizes the results of analysis. Following DTM and DTT have been presented in this table: 'theory of inventive problem solving' (TRIZ), axiomatic design (AD), function-behavior-structure (FBS), functional analysis (FA), quality function deployment (QFD), computer-aided design (CAD), and Risk analysis techniques

The literature shows that design for human safety is a very complicated subject characterized by several factors including systemic, human and environmental ones. Consequently, designers tend to use tools and techniques that normally focus on the use of a product and not only its design. The literature reviews also showed that the conditions of utilization are not or are hardly taken into account during the design phase, and that there is always a gap between what is imagined in the design and what is experienced when using the product. Indeed, one of the main sources of risk is linked to the variety of work situations. To take into account this variety, the aim in design is to take into account human behaviors demonstrated in work situations in parallel with the product, so as not to focus only on product design or only on designing human activities.

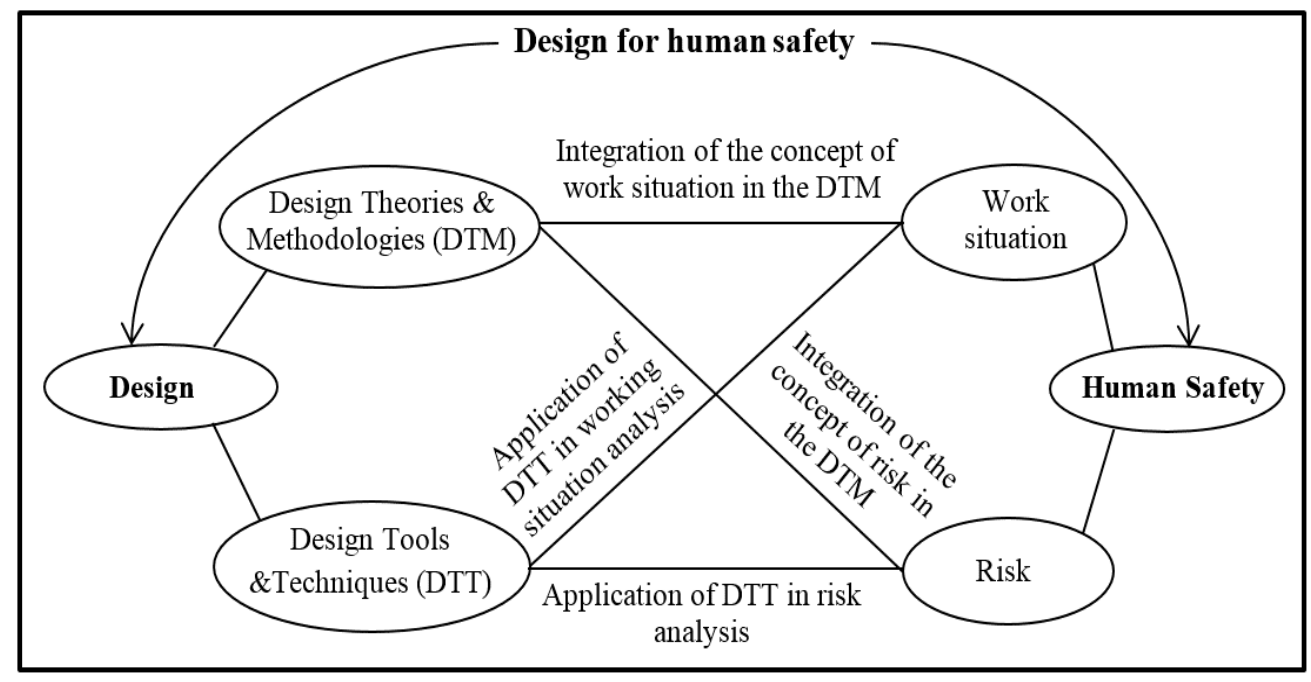

Figure 3. Framework of DfHS (Sadeghi et al. 2016) 
Table 1. Review on applications of DTM/ DTT in DfHS (from (Sadeghi et al. 2016))

\begin{tabular}{|c|c|c|c|c|c|}
\hline \multicolumn{2}{|c|}{$\begin{array}{l}\text { DTM / } \\
\text { DTT }\end{array}$} & \multirow{2}{*}{$\begin{array}{l}\text { Reference } \\
\text { (Marsot and Claudon 2004) }\end{array}$} & \multirow{2}{*}{$\begin{array}{l}\text { Design phase } \\
\text { From conceptual design }\end{array}$} & \multirow{2}{*}{ 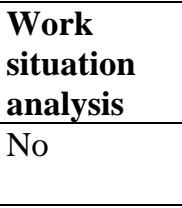 } & $\begin{array}{l}\text { Integration with } \\
\text { other DTM \& } \\
\text { DTT\& techniques }\end{array}$ \\
\hline \multirow{13}{*}{ 空 } & \multirow{4}{*}{$\frac{N}{F}$} & & & & $\begin{array}{l}\text { Functional } \\
\text { Analysis and QFD }\end{array}$ \\
\hline & & (Hasan et al. 2004) & From conceptual design & Not explicit & - \\
\hline & & $\begin{array}{l}\text { (Houssin and Coulibaly } \\
\text { 2011) }\end{array}$ & From conceptual design & Not explicit & - \\
\hline & & (Sadeghi 2014) & From conceptual design & Not explicit & $\begin{array}{l}\text { Systematic } \\
\text { approach, AD, } \\
\text { FTA }\end{array}$ \\
\hline & \multirow{8}{*}{ \& } & (Helander and Lin 2000) & From embodiment design & Not explicit & - \\
\hline & & (Helander and Lin 2002) & From embodiment design & Not explicit & - \\
\hline & & (Helander and Jiao 2002) & From embodiment design & Not explicit & - \\
\hline & & (Karwowski 2005) & From embodiment design & No & - \\
\hline & & (Heo and Lee 2007) & From embodiment design & No & - \\
\hline & & $\begin{array}{l}\text { (Helander 2007; Lo and } \\
\text { Helander 2007) }\end{array}$ & From embodiment design & No & - \\
\hline & & (Ghemraoui et al. 2009a) & From conceptual design & Not explicit & $\begin{array}{l}\text { Systematic } \\
\text { approach }\end{array}$ \\
\hline & & $\begin{array}{l}\text { (Sadeghi et al. 2013a; } \\
\text { 2013b; 2015) (Sadeghi, } \\
\text { 2014) }\end{array}$ & From conceptual design & Not explicit & $\begin{array}{l}\text { Systematic } \\
\text { approach, FTA, } \\
\text { TRIZ }\end{array}$ \\
\hline & $\tilde{\infty}$ & $\begin{array}{l}\text { (Houssin et al. 2010; Sun et } \\
\text { al. 2013) }\end{array}$ & $\begin{array}{l}\text { Behavior analysis in } \\
\text { detailed design }\end{array}$ & Yes & $\begin{array}{l}\text { Functional } \\
\text { analysis, AD }\end{array}$ \\
\hline \multirow{22}{*}{$\stackrel{E^{2}}{\circ}$} & \multirow[t]{2}{*}{ 质 } & (Jouffroy et al. 1999) & From conceptual design & No & $\begin{array}{l}\text { Ergonomic } \\
\text { approach }\end{array}$ \\
\hline & & (Marsot and Claudon 2004) & From conceptual design & No & QFD and TRIZ \\
\hline & \multirow{4}{*}{ 完 } & (Marsot and Claudon 2004) & From conceptual design & No & $\begin{array}{l}\text { Functional } \\
\text { Analysis and TRIZ }\end{array}$ \\
\hline & & (Marsot 2005) & From conceptual design & No & - \\
\hline & & (Liu and Tsai 2012) & Detailed design & No & $\begin{array}{lr}\text { Analytic } & \text { Network } \\
\text { Process } & \text { (ANP), } \\
\text { FMEA } & \\
\end{array}$ \\
\hline & & (Bas 2014) & Detailed design & No & - \\
\hline & \multirow{8}{*}{ 这 } & (Hasan et al. 2003) & From conceptual design & Not explicit & - \\
\hline & & (Shahrokhi 2006) & Detailed design & Not explicit & ETA \\
\hline & & (Houssin et al. 2006) & From conceptual design & Not explicit & - \\
\hline & & (Määttä 2007) & Detailed design & Not explicit & $\begin{array}{l}\text { Participatory } \\
\text { Ergonomics }\end{array}$ \\
\hline & & (Marsot et al. 2007) & From conceptual design & No & Risk-indexing tool \\
\hline & & (Coulibaly et al. 2008) & Detailed design & Not explicit & - \\
\hline & & (Houssin and Cardoni 2009) & Detailed design & Not explicit & - \\
\hline & & $\begin{array}{l}\text { (Shahrokhi and Bernard } \\
\text { 2009) }\end{array}$ & Detailed design & Not explicit & - \\
\hline & \multirow{8}{*}{ 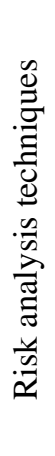 } & (Harms-Ringdahl 1987) & Detailed design & No & Not specific \\
\hline & & Schoone-Harmsen (1990) & Detailed design & No & Not specific \\
\hline & & (Stoop 1990) & Detailed design & No & Not specific \\
\hline & & $\begin{array}{l}\text { (Gauthier and Charron } \\
\text { 2002) }\end{array}$ & Detailed design & Not explicit & FTA \\
\hline & & $\begin{array}{l}\text { (Shahrokhi and Bernard } \\
\text { 2010) }\end{array}$ & Detailed design & No & ETA, FTA \\
\hline & & (Village et al. 2011) & Detailed design & & FMEA \\
\hline & & (Sadeghi 2014) & $\begin{array}{l}\text { From conceptual design } \\
\text { phase }\end{array}$ & Not explicit & FTA \\
\hline & & (Lux et al.2015) & Detailed design & Not explicit & FMEA \\
\hline
\end{tabular}


The function allocation to the product part, the service part, or a combination of both should be determined. Therefore, we need a design theory which models this allocation of functions. By looking far beyond these review developments on DTM, our expect to "safe design" can be achieved by using the FBS, which covers behavior, seems appropriate to include product and its utilization. FBS theory emphasizes the need to consider human performance in the design process, thus permitting work situation analysis.

The application of FBS in human safety has been relatively rare. The authors of (Houssin, Sun, and Gardoni 2010; Sun et al. 2013) focused on integrating the utilization conditions of mechanical products in the design process. In (Houssin et al. 2010) they proposed a global view of the Behavioral Design Approach (BDA) to help designers to analyze the interaction between user tasks and technical tasks, to evaluate system performance and find potential hazards. Then, in order to build a computer-aided system based on the BDA, they proposed a system framework for the BDA based on the hierarchical information model for engineering design (Sun et al. 2013). The UML was used to model the BDA system (Sun et al. 2013), by translating behavioral design modelling and their information models into computer language.

In these works, the behavior concept of FBS was used to define system (structure) behavior and user behavior. Analyzing the integration of these two behaviors allows determining the global behavior in a work situation. However, this analysis is more useful for making comparisons than for creating designs. It should be noted that here, user behavior concerns the user's task and does not include the service done by them. To overcome the shortcomings of these works, FBS can be integrated with Product-Service Systems (PSS). 
It extends the traditional functionality of a product by incorporating additional services. There are mainly three kinds of PSSs considered in literature ( Yang, Moore, $\mathrm{Pu}, \&$ Wong, 2009):

- Product-oriented PSS: A product is enhanced with services as a support of its use along its life-cycle from the selling (e.g. financial facilities) to the disposal (e.g. recycling). The client owns the product and has the possibility to buy additional services to improve his experience. The product is little, or not, impacted by these service additions. Its lifetime is expected to be improved compared to a standard manufacturing product (Cook et al. 2006).

- Use-oriented PSS: A product is no longer sold to the client; it remains the property of the provider. The client benefits from its use over a determined period he paid for. The product is impacted in its design as the main purpose is to have high usage intensity to generate income (Yang et al. 2009). There is service integration to a usable/available product. This integration requires a re-engineering of an existing product to adapt some of its properties in terms of robustness and integrity.

- Result-oriented PSS: The product is no longer an issue for the client, only the quality of the result is. A functionality provided by a product is replaced by a pure service. There is service substitution (Sundin et al. 2009) to a buyable product. In this case, the providers' degree of expertise about the product's use is somehow highlighted or recognized which guarantees a higher efficiency. Consumer goods become professional equipment which requires high technical skills when manipulated. 
In terms of business models, the main difference between each one could be synthesized into the degree of ownership sold to the consumer: property of the product, property of its use, and property of its results (Cook et al. 2006). It demonstrates a shift in business strategy from a product-oriented to a service-oriented focus (Tan et al. 2009) where the value of the product is transferred to its utility or purpose (i.e. the result) from the client's perspective (Vasantha et al. 2012).

We are interested in use of PSS in this research because this research study is looking at the interaction between product and service. According to (Baines et al. 2007) a PSS is an integrated product and service offering that delivers value in use to the customer. They highlight the aim of PSS is to value asset performance rather than ownership and differentiation through the integration of products and services. Therefore, PSS could be used as a model to represent the defined "operating system" composed of interdependent product parts (e.g. component) and service parts (i.e. human-intensive activity).

The PSS which represents one of the product parts depends on its definition to the service part. In this research, the scope of the object of study is not limited to a physical artefact but enlarged to the service provided through it. Unlike a product, service components are often not physical entities. In PSS concept, service is incorporated into the design space, which has been traditionally dominated by products. Its integration in the scope introduces a new complexity in the requirements definition of the system. The object of study is then considered as an "operating system". The dependency between these two parts and their mutual integration should be developed in our study.

\subsection{Research objective}

FBS modelling covers the aspect of behavior and models this allocation of functions. Regarding the PSS paradigm, they made a distinction between two kinds of behaviors: 
service behaviors and product behaviors. In other words, the interaction between PSS and FBS allows considering product behaviors and their interaction with service behaviors. The analysis of interaction between PSS and FBS allows considering any user activity performed in a work situation. The aim is to design human behaviors and products in parallel, not by designing only products or designing only human activities. This allows identifying and analyzing the work situation from the conceptual design phase.

Our system is composed of a dynamic service part and a static product part modelled in the PSS paradigm. With this PSS paradigm comes a new issue relevant to the conceptual design phase of PSS development: the function allocation to the product part, the service part, or, in our case, a combination of both. We need a design theory which models this allocation of functions. In the next section, a literature review on design theories and methodologies will be presented to select the appropriate one for our research.

The FBS modelling covers behavior aspect and models this allocation of functions. Regarding the PSS paradigm, they did a distinction between two kinds of behaviors: behaviors of the service and behaviors of the product. In other words, the interaction between PSS and FBS allows considering product behaviors and its interaction with service behaviors. The analysis of interaction between PSS and FBS allows considering any user activity performed in working situation. The aim is designing human behaviors and products in parallel, neither designing only products nor designing human activities. This allows identifying and analyzing working situation form conceptual design phase.

Next section proposes a design approach for safety based on interaction between PSS and FBS which allows integrate working situation into design from earliest design phases. 


\title{
3. Design for human safety based FBS and PSS
}

The basis of this proposition is Gero's FBS paradigm applied to structure more precisely the requirements definition of systems with the following definitions (Kannengiesser \& Gero 2011):

- Function - Teleology of the artefact, what is it for.

- Behavior - Attributes derivable from the structure, what it does.

- Structure - Components and their relationships of an artefact, what it consist of.

The FBS "ontology" is not limited to the description of the design objects. This framework is also used to model the design process (Gero \& Kannengiesser 2004) as precise as possible. Figure 4 shows the eight fundamental processes of Gero's FBS.

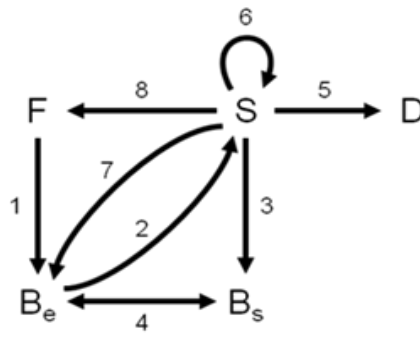

\author{
F: Function \\ $\mathrm{B}_{\mathrm{e}}$ : set of expected behaviours \\ $\mathrm{B}_{\mathrm{s}}$ : set of actual behaviours \\ S: Structure \\ D: Design description
}

Figure 4. Gero’s FBS framework (Gero 1990)

The starting point was originally the concept of Function as the purpose of the system to design. Later, it changed to become the concept of Requirement, an input given to the designer by the customer that indicates the design problem. The last step of the design process (i.e. the description of the design, e.g. CAD drawings and component lists) used for construction or manufacture.

In FBS modelling a function is defined as a description of behaviors abstracted by human through recognition of the behaviors in order to utilize it (Umeda et al. 1990) and represented as an association of two concepts: symbol of human intention represented in the form of to do something, and behaviors that can exhibit the function. The basis of 
this proposition is Gero's FBS “ontology" applied to structure more precisely the requirements definition of systems with the following agreed upon definitions based on (Kannengiesser \& Gero 2011):

- Function - What the system should be able to achieve expressed in terms of purpose, what it is for.

- Behavior - How the system is expected to perform its functions and when. It describes how the system and its components perform.

- Structure - Who performs the functions inside the system, which components, and their relationships. It describes the internal composition of the system, what it physically is, but also where it is in the construction.

Regarding the PSS paradigm, therefore, we make a distinction between two kinds of behaviors: behaviors of the Service part (i.e. Activity) and behaviors of the Product part (i.e. attribute derivable from the structure). A Behavior is an activity (action or reaction) or a property of a system (or subsystem) under certain circumstances or triggering events, associated with or derived from its Structure (i.e. its components) explaining the How and When does/can the system perform a Function?. Structure refers to physical and virtual components of the system, their (static) description (i.e. characteristics), and their relationships describing what it is composed of, more generally answering the Who (i.e. which resource) has to act in the system to perform a Function when needed, and Where is it performed?

The behavior includes the concept of product properties. A product property represents a "passive" behavior that can realize a function. It is an alternative to an activity which can be considered as an "active" behavior of the PSS system. Therefore, we 
propose to use the Behavior construct to model and support the function allocation to the product part through properties or the service part through activities of our systems.

The FBS paradigm developed by Gero models the design process using relationships between three main constructs: Function, Behavior, and Structure (Gero 1990). This FBS paradigm is used as a basis to model and structure the transition from needs to requirements and the allocation of functions to the different parts of our system. Some researchers proposed FBS models. Christophe et al. extends the FBS model and presents its practical implementation through ontology and SysML language (Christophe et al. 2010). Labrousse and Bernard proposed a generic and structuring model based on the FBS concepts. These concepts are applied to four objects (PPRE): the Processes, the Products (objects stemming from the processes), the Resources (objects needed to realize the processes) and the External effects (constraints having an influence on the processes) (Labrousse \& Bernard 2008). Qin et al. developed knowledge representation model, based on FBS, for capturing useful design knowledge and experience for future reuse which is named Requirement-Function-Behaviour-Structure-Evolution (RFBSE) knowledge(Qin et al. 2017). Regarding the PSS paradigm, we, therefore, make a distinction between two kinds of behaviors: behaviors of the service part and behaviors of the product part.

\subsection{Proposed approach}

This section proposes a modelling of the transitions between FBS and PSS paradigm to distinguish the realization of functions by a product part, a service part or a combination of both. Based on the additional construct and definition, the conceptual model of the definition domain has to be updated to reflect the changes. Goals are still achieved by functions. Functions are now realized through behaviors. The behaviors can be either an activity (i.e. behavior associated to the service part), or a property (i.e. behavior associated 
to the product part). Behaviors are assigned to a structure element which can be a human or material resource, or a space. The proposed approach is decomposed into 6 steps (Figure 5).

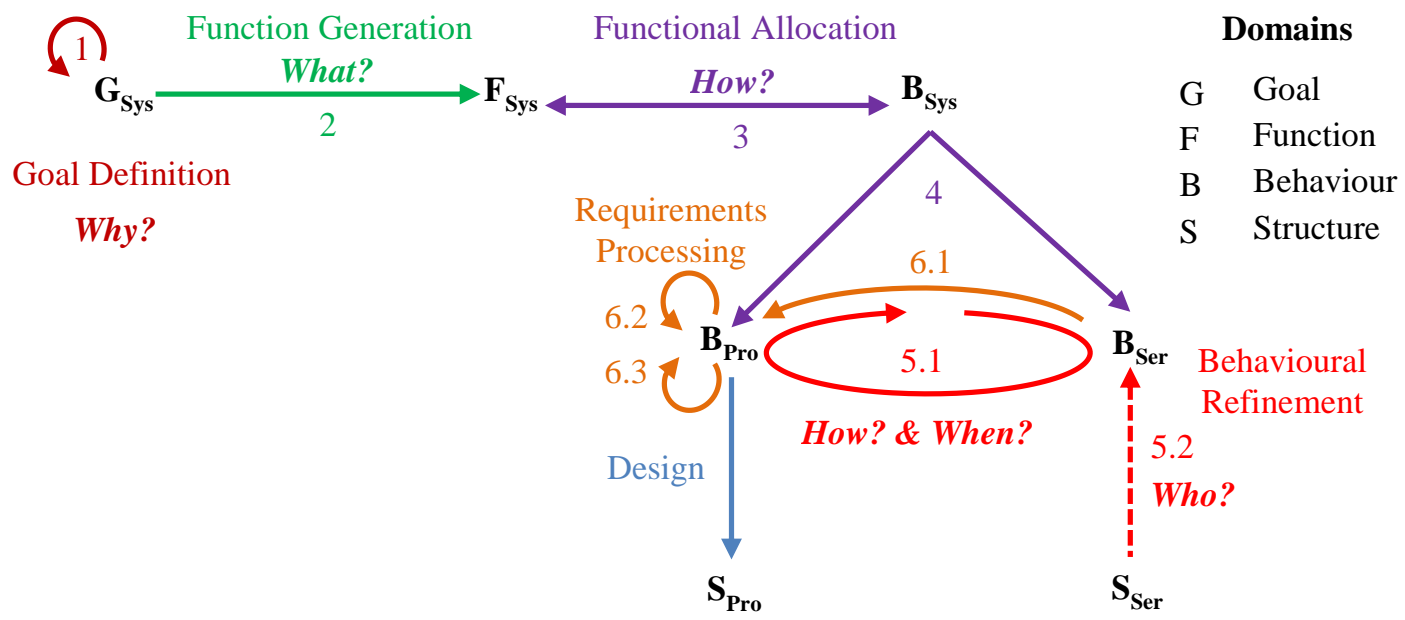

Figure 5. The proposed design for human safety approach

Step 1. Goal definition: Goals represent the desired state of affair or condition to achieve through the system's creation. Goals of the System $\left(\mathrm{G}_{\text {sys }}\right)$ are the input of the design process; they are defined and refined with the client. Goals drive the decisions along the framework.

Step 2. Function generation: When a goal cannot be further refined, a function ( $\left.F_{\text {Sys }}\right)$ has to be formulated to express what the system should do to attain this goal. During this step, the designer transforms states of affairs or conditions of the environment to achieve or maintain into abilities of action by the system, independently from the technical solutions.

Step 3 and Step 4. Function allocation: The objective is to define how functions will be implemented in terms of behaviors associated to main structure elements. The function allocation to either $\mathrm{S}_{\mathrm{Pro}}$ or $\mathrm{S}_{\mathrm{Ser}}$ consists in refining the $\mathrm{B}_{\mathrm{Sys}}$ into Behaviors of the Product $\left(\mathrm{B}_{\text {Pro }}\right)$ and Service $\left(\mathrm{B}_{\text {Ser }}\right)$ parts. After knowing what the system $\left(\mathrm{S}_{\text {Sys }}\right)$ should do $\left(\mathrm{F}_{\text {Sys }}\right)$, it is necessary to define how it will be done but also to detail which part of it will 
do it (i.e. $\mathrm{S}_{\text {Pro }}$ or $\mathrm{S}_{\mathrm{Ser}}$ ). A Function is performed (3) through Behavior of the system (BSys) seen as a black box. The function allocation to either $\mathrm{S}_{\text {Pro }}$ or $\mathrm{S}_{\mathrm{Ser}}$ consists in refining the $\mathrm{B}_{\text {Sys }}(4)$ into Behaviors of the Product $\left(\mathrm{B}_{\text {Pro }}\right)$ and Service $\left(\mathrm{B}_{\text {Ser }}\right)$ parts. It corresponds to the definition of the design strategy of the system $\left(\mathrm{S}_{\mathrm{Sys}}\right)$.

Step 5. Behavioral refinement: The behavioral refinement consists in describing the internal functioning (5.1) of the $S_{S y s}$ necessary to fulfil the $F_{S y s}$ allowing the achievement of the $\mathrm{G}_{\text {Sys }}$ in terms of its components' behavior ( $\mathrm{B}_{\text {Ser }}$ and $\left.\mathrm{B}_{\text {Pro }}\right)$. These behaviors refer to processes and activities to be performed (5.2) by a set of resources $\left(\mathrm{S}_{\mathrm{Ser}}\right.$ and $\left.\mathrm{S}_{\text {Pro }}\right)$. Each activity and resource requires certain conditions to be performed or used.

Step 6. Processing (or Behavior-Structure balance): The behavioral refinement generates a lot of information. The objective of the processing is to reduce the amount of requirements. At this step, dependencies between behaviors and structure elements are checked for requirements consistency with the clients (e.g. limited number of structure elements can only ensure limited number of behaviors). A balance between them is performed to modify, reduce or delete requirements on the system according to the defined goals. The requirements processing is performed in three steps. The main principle is that each operation is defined with a set of constraints and requirements. In order to manipulate the requirements, a design artefact is introduced: the meta-space. A meta-space regroups all the requirements about an operation to perform. Therefore, an operational meta-space gathering all the necessary conditions is assigned to each operation (6.1). This operational meta-space is considered as part of the product's behavior $\left(\mathrm{B}_{\mathrm{Pro}}\right)$. As a result, there are as many operational meta-spaces as operations to perform. Based on information about the processes ( $\mathrm{B}_{\text {Ser }}$ and $\left.\mathrm{B}_{\text {Sys }}\right)$, the operational metaspaces can be linked to each other (6.2). The amount of operational meta-spaces is reduced through their grouping based on their conditions (6.3). 


\subsection{Model used}

The objective of this section is to modelling product and services behaviors in order to help working situation analysis. To this aim, we focus just on step 5 (Behavioral refinement) and step 6 (Processing) of proposed approach.

\subsubsection{Behaviors identification}

As mentioned previously Product behavior $\left(\mathrm{B}_{\mathrm{Pro}}\right)$ refer to expected behaviors of the product part of the system under specific conditions. Pailhès et al. (2011) used energy term to identify the action that the system must carry out to the function that this system must achieve. They proposed four following behaviors:

- Convert (C) imported energy into energy, that is, usable by the other system components (input energy is type 1 and output energy is type 2);

- Transmit (T) energy to with no change in energy type (input and output energy are identical type 2);

- Operate (O) the action required by the system or the unit using transmitter output power; and

- Control-command $(\mathbf{C} / \mathbf{C})$ to ensure that the functions of the different components are properly carried out.

These elements have been shown in Figure 6.

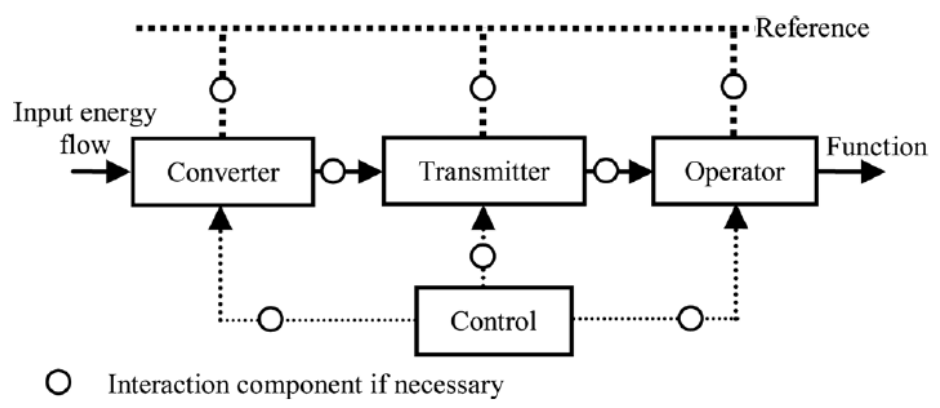

Figure 6. Energetic view of the law of completeness of system parts (Pailhès et al., 
In addition of these four product behaviors, we add three other:

- $\quad$ Protect $(\mathrm{P})$ persons from the hazards;

- $\quad$ Transfer $(\mathrm{T})$ the place of product;

- Connect $(\mathrm{C})$ one product to another one.

Therefore, in this paper, product behaviors are considered: Convert energy, Transmit energy, Operate, Control, Pr3otect, Transfer, Connect (CTOC-PTC).

Service behavior $\left(\mathrm{B}_{\mathrm{Ser}}\right)$ describe expected behaviors of the service part of the system. Several classifications of the sub-phases of the system's use phase exist. For the use phase (Caputo et al. 2013), the term "operational phase" is used and includes the following activities: installation, operation, cleaning, maintenance and decommissioning. A classification is adopted grouping all the activities and states of the system's five subphases: assembly, installation, commissioning (e.g. towing, connection, mounting), transport (e.g. moving the system from storage to the place of use, loading and unloading the system, setting the system's transportation configuration, etc.), use (e.g. start-up and operation of the system, setting and controlled operation), dismantling, decommissioning (e.g. disconnection, uncoupling between two storage uses) and maintenance (e.g. maintenance, lubrication, cleaning, fault finding, repair). In this paper $\mathrm{B}_{\text {Ser }}$ limited into: Displacement, Install, Operate, Repair, Inspect, and Maintain.

$\mathrm{B}_{\text {Pro }}$ and $\mathrm{B}_{\text {Ser }}$ are two separate but interrelated sets of descriptions, so the dependency relationships between and within $\mathrm{B}_{\text {Pro }}$ and $\mathrm{B}_{\text {Ser }}$ are much more complicated than in simple product or service design. In order to illustrate the interaction between $\mathrm{B}_{\text {Pro }}$ and $\mathrm{B}_{\mathrm{Ser}}$, we propose a diagram named proximity diagram consists of two circles in which one CTOC-PTC of system is placed in the center of them. These circles show working situation and the existence of relationships between users and one CTOC-PTC of system. The activities which are performed on the part are presented in inner circle and outer 
circle includes the activities which are performed near the product (not on the product directly). Indeed, each activity is connected to the product with an arrow and its duration and frequency are illustrated in the parenthesis on the corresponding arrow. Reduction of the frequency and/or duration of exposure to hazard are depicted in the standard as an alternative of eliminating hazardous situation. The frequency and duration of exposure to CTOC-PTC of system should be considered in working situation analysis. A simple of proximity diagram is shown in Figure 7 . This diagram will be applied to working situation analysis in the next section.

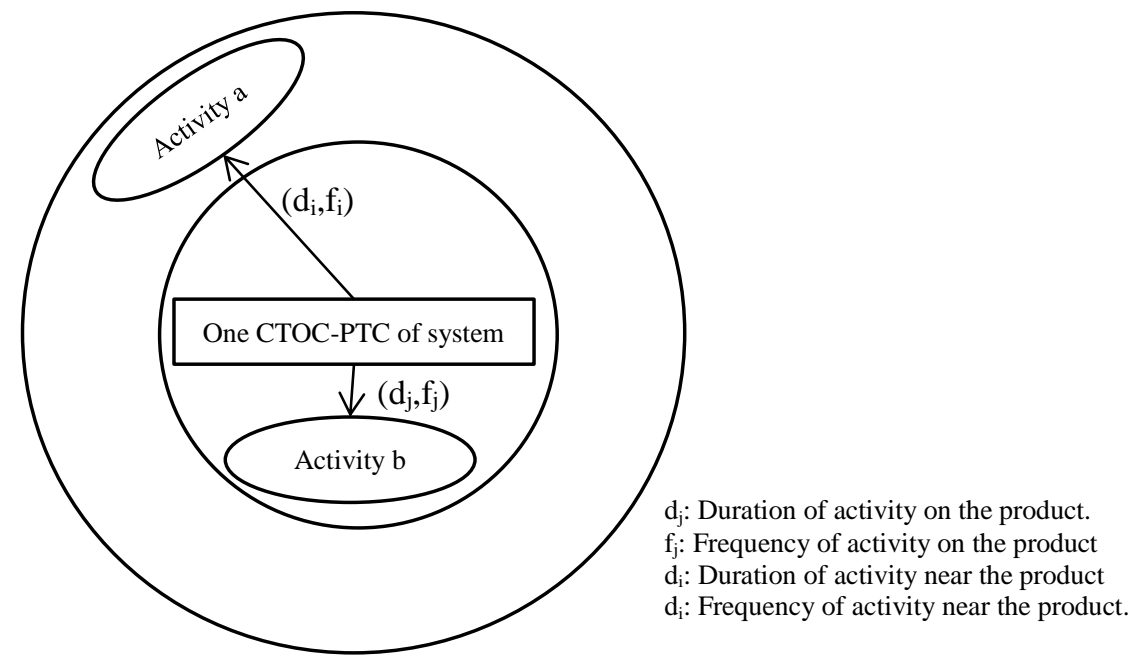

Figure 7. Proximity diagram

\subsubsection{Behavior modelling}

The effective integration of product behaviors and service behaviors (product/service system) is essential to working situation analysis. Service behaviors $\left(\mathrm{B}_{\text {Ser }}\right)$ helps to risk analysis related to user activity performed in working situation. The question that arises is: How to analyze the risk? A key aspect of safety improvement is the use of past experiences (experience feedbacks), such as incidents and accidents. The accidents investigation aims at discovering the causes that led to the accident in question. Accident investigation is thus an essential first step in the design and implementation of adequate preventive measures, with the objective of preventing similar accidents from 
occurring again (Johnson \& Holloway 2003). Therefore, understanding the causes of accident in the work place is an essential step toward DfHS.

Accident scenario definitions help to describe the reasons of accidents occurrence. One of the documents for describing the accident scenario is called the accident report. Accident reports provide details on factors that can cause harm. On the other hand, hazardous conditions can be identified based on information from accident reports. After analysis of different accident reports, Sadeghi et al. listed the following information useful for hazardous conditions identification: type of harm, type of accident (its consequences and origin), and conditions of accident (usage phase, task, state of machine, unintended behavior of the operator, the presence of others, environment conditions) (Table 2) (Sadeghi et al. 2015). This table allows gathering, in a synthetic representation, all the elements that contributed to an accident.

Table 2. Accident analysis information

\begin{tabular}{|c|c|c|}
\hline & & Information related to accident \\
\hline \multicolumn{2}{|l|}{ Harm } & $\begin{array}{ll}\text { - } & \text { The affected body part } \\
\text { - } & \text { Type of injury }\end{array}$ \\
\hline \multicolumn{2}{|c|}{ Type of accident } & $\begin{array}{ll} & \text { Consequence of accident } \\
- & \text { Source of accident }\end{array}$ \\
\hline \multirow[t]{3}{*}{$\begin{array}{l}\text { Conditions } \\
\text { of accident }\end{array}$} & $\begin{array}{l}\text { Operating conditions } \\
\text { of the system }\end{array}$ & $\begin{array}{ll}- & \text { Use phase } \\
- & \text { Operator's task } \\
\text { - } & \text { State of the machine }\end{array}$ \\
\hline & $\begin{array}{l}\text { Behavior and } \\
\text { capabilities of operator }\end{array}$ & $\begin{array}{ll}\text { - } & \text { Operator's behavior } \\
\text { - } & \text { Operator's capabilities }\end{array}$ \\
\hline & $\begin{array}{l}\text { Environment } \\
\text { conditions }\end{array}$ & $\begin{array}{l}\text { - The presence of other persons (unrelated to the } \\
\text { task) } \\
\text { - } \quad \text { The open or closed environment } \\
\text { - } \quad \text { Structured or outdoor environment }\end{array}$ \\
\hline
\end{tabular}

If service behavior develops an accident, the question that arises at this point is:

How can mitigate the risk? To mitigate the risk three solutions could be proposed (Figure 8):

- Modifying product behavior. First solution could be replacing the $\mathrm{B}_{\text {Pro }}$ with another safer B Bro. For example, to prevent entanglement with rotating element, replace this element with another element like hydraulic element. Here, the 
designer must stay in the same hierarchical level of Product-Service decomposition and the looking for $\mathrm{B}_{\text {Pro. }}$ This search step of removing the hazard can bring the designer to provide innovative design solutions. At this stage, it is difficult for the designer to judge the safety of new solution.

- Adding new product behavior. Second solution to mitigate the risk is to add another BPro related to the hazard. For example, add safety protection to prevent risk related to entanglement with rotating element. Here, the designer must seek to eliminate access to the hazardous zone. By applying this solution a parallel design process can be started.

- Modifying service behavior. Risk mitigation can be achieved through modifying service behavior $\left(\mathrm{B}_{\mathrm{Ser}}\right)$.

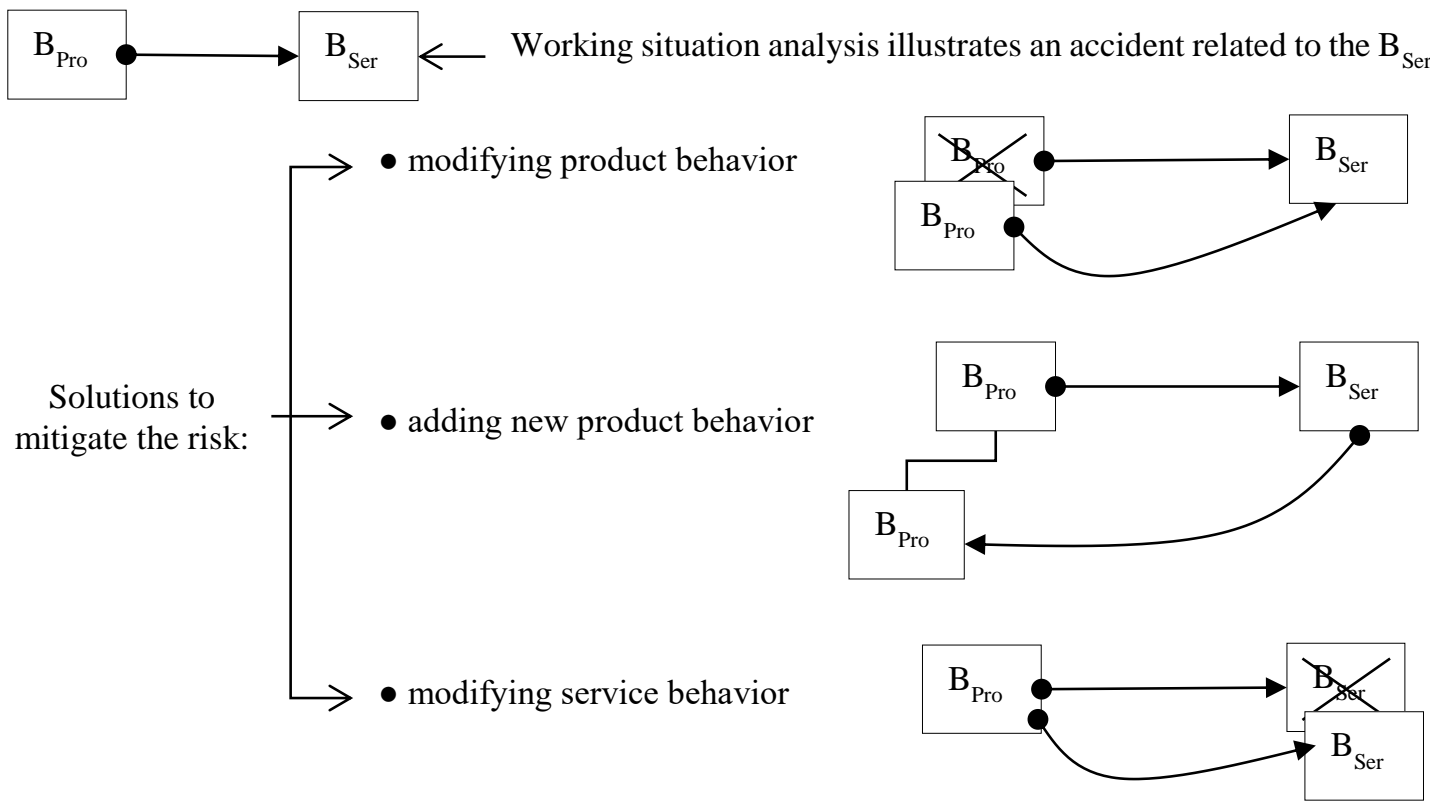

Figure 8. Risk mitigation through three solutions

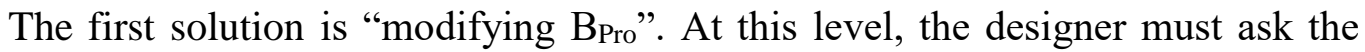
question: "Can the BPro be modified and is this desired?" If the answer is positive, the solution is set. If the answer is negative, the question that the designer must ask is: "Can new B Pro be added and is this desired?" If the answer is positive, the target is set. Otherwise, proceed to the following solution, "modifying Bser". 
These three solutions allow designing human activities in parallel with products, neither designing only products nor designing human activities after products. This is the advantages of safety improvement during design process based on FBS rather than another research works. In a working situation, this zone is created by a system or component carrying out an operation or running off-load. For each $\mathrm{B}_{\mathrm{Ser}}$, the associated accidents and hazards in the working situation should be defined. After the hazard(s) is (are) identified, designer can mitigate the risk related to this (these) hazard(s) through two different solutions.

The new solution is chosen, it is necessary to ensure safety until the end of the design process. In the end of design, if there are still safety problems not solved following this approach, they must be translated in the form of recommendations. These recommendations for operators, aim to guide them to a good and safe use of the system.

\section{Case study: Power Take-Off (PTO) drive shaft}

Currently, the farming sector constitutes a serious problem in the domain of human safety. In this sector, one of the main sources of safety risks is related to Power Take-Off (PTO) drive shaft. Figure 9 shows a PTO drive shaft. The PTO drive shaft a removable device for transmission mechanical energy connected to the tractor and to the implement provided at the rear of a tractor by Power-Input Connection (PIC).

The existing PTO drive shaft is the result of almost one century of technical evolution and more than 80 years of safety evolution. Nevertheless, along with the extensive work done to improve the safety of PTO, this system is one of the oldest and most persistent hazards associated with agricultural machinery, and it is extremely dangerous even with safeguards. The patent evolution confirms the first concept (using the rotating element to transform tractor energy to implement) has not changed and thus, 
more patents have been investigated to improve the PTO drive shaft from the safety point of view.

From the side of the tractor PTO drive shaft From the side of the implement

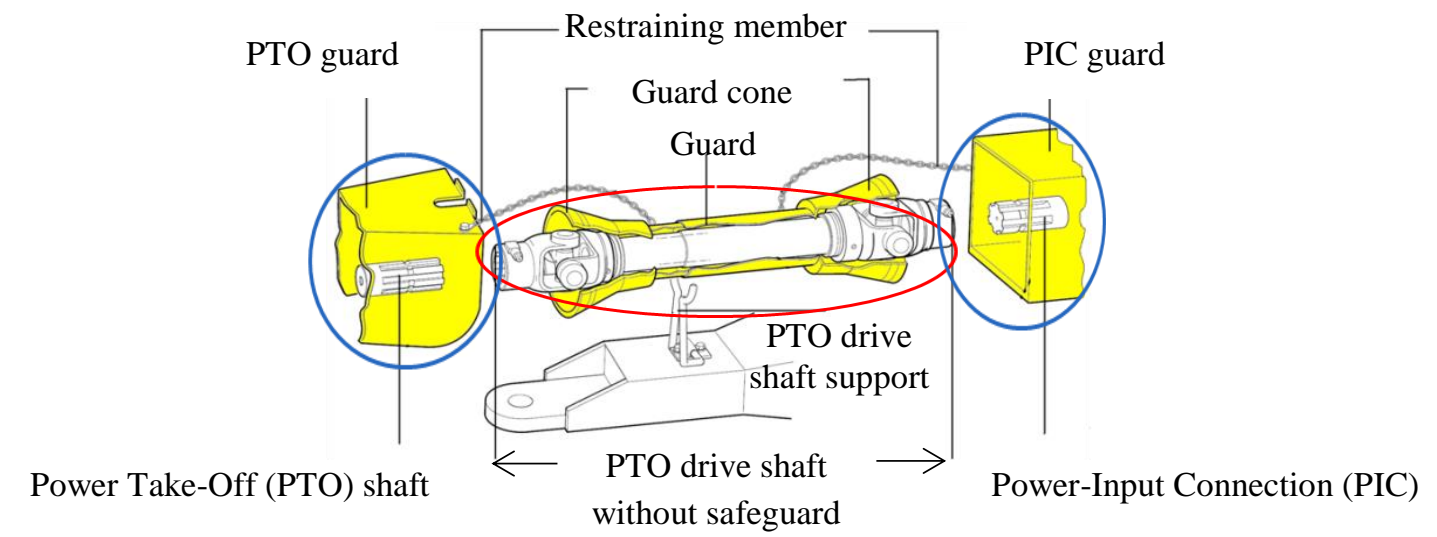

Figure 9. Power Take-Off (PTO) drive shaft (Sadeghi et al. 2015)

The accident analysis shows that a person is at an increased risk of having an accident if they are in the vicinity of a PTO system with a missing, broken, damaged or poor fitting safeguard (Sadeghi et al. 2013; Sadeghi et al. 2015). Table 3 shows the results of one selected accident report analysis related to this system.

Table 3. The results of a PTO drive shaft accident analysis

\begin{tabular}{|l|l|l|}
\cline { 3 - 3 } \multicolumn{2}{|l|}{ Harm } & Accident \\
\hline \multicolumn{2}{|l|}{ Type of accident } & - Death \\
\hline $\begin{array}{l}\text { Conditions } \\
\text { of accident }\end{array}$ & $\begin{array}{l}\text { Operating } \\
\text { conditions of } \\
\text { system }\end{array}$ & $\begin{array}{l}\text { - Origin of accident: rotating element } \\
\text { - Task: the victim and another person were making concrete with a } \\
\text { cement mixer driven by a shaft connected to the PTO of the tractor } \\
\text { - State of the machine: operated normally but with a broken guard }\end{array}$ \\
\cline { 2 - 3 } & $\begin{array}{l}\text { Behavior and } \\
\text { capabilities of } \\
\text { operator }\end{array}$ & $\begin{array}{l}\text { - Unintended behavior of the operator: operator had been trained in } \\
\text { how to use the machine, he was experienced, he had no physical } \\
\text { limitations, but he was in a stressful condition. }\end{array}$ \\
\cline { 2 - 3 } & $\begin{array}{l}\text { Environment } \\
\text { conditions }\end{array}$ & $\begin{array}{l}\text { - The presence of other persons than the operator } \\
\text { - Open environment } \\
\text { - Outdoor environment }\end{array}$ \\
\hline
\end{tabular}


Figure 10 shows CTOC-PTC diagram for PTO drive shaft. For this product, input and output energy are mechanical energy.

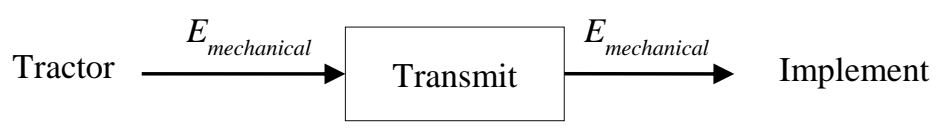

Figure 10. CTOC-PTC diagram for PTO drive shaft

The proximity diagram related to the accident related to this system is shown in

Figure 11. The operator exposure time near the hazard for a complete cycle is, on average, $8 \mathrm{~h}$ for $12 \mathrm{~h}$ work cycle. The analysis of the accident report shows that accident result in entanglement of the operator around the PTO drive shaft with a broken safeguard during its utilization.

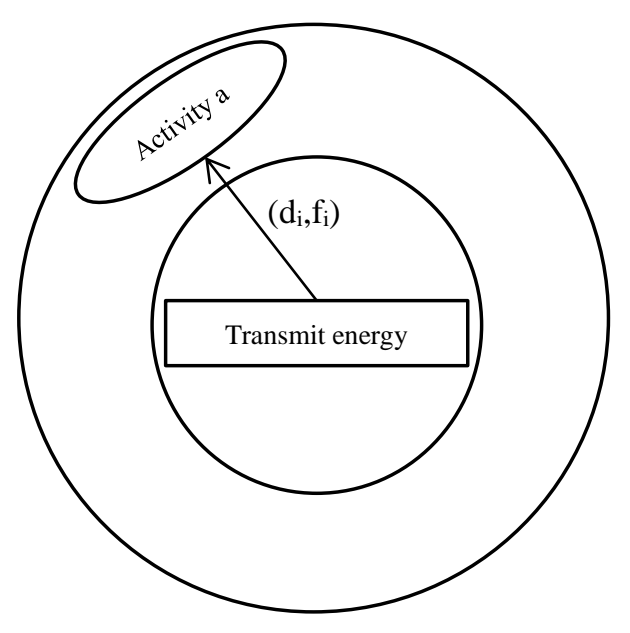

Activity a: the victim and another person were making concrete with a cement mixer driven by a shaft connected to the PTO of the tractor

$\mathrm{d}_{\mathrm{i}}$ : Duration of activity near the part $\mathrm{d}_{\mathrm{i}}$ : Frequency of activity near the part

Figure 11. Proximity diagram for PTO drive shaft

The accident analysis confirms that PTO drive shaft safeguards still don't ensure human safety. A person is at an increased risk of having an accident if they are in the vicinity of a PTO system with a missing, broken, damaged or poor fitting safeguard. In fact, in the case of missing, broken, damaged or badly fitting safeguards of the system, 
this system will be very dangerous (Sadeghi et al. 2013) and workers will be killed or injured as a result of contact with rotating element (Figure 12).

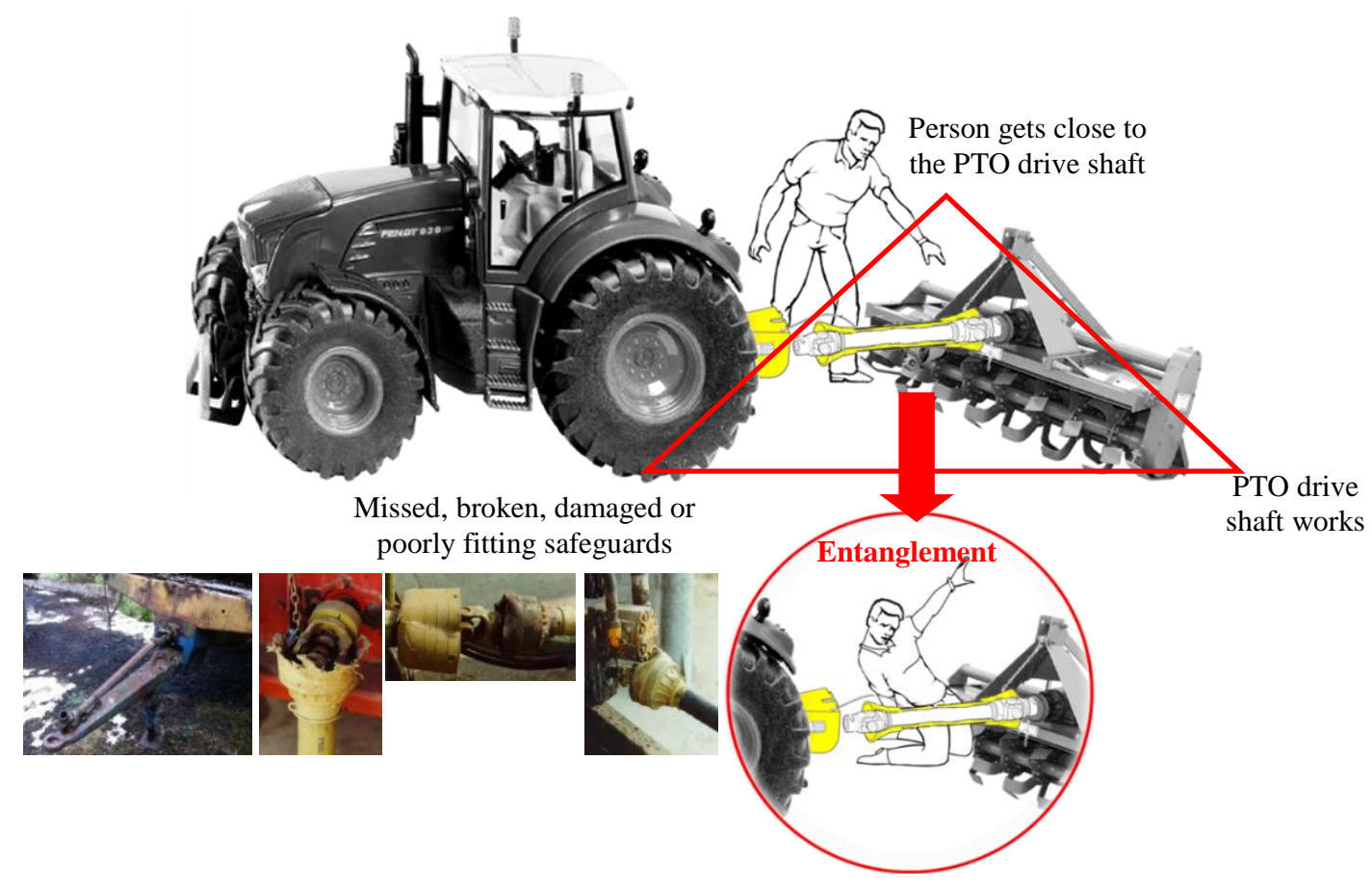

Figure 12. Accident analysis results

The accident cause is related to performing an activity by person on or around the PTO drive shaft. Whereas, the rotating element is the origin of entanglement therefore the risk related to this hazard must to be mitigated. To achieve this aim, as illustrated in Figure 13, there are three solutions:

- The first solution (a): replace rotating element $\left(\mathrm{B}_{\text {Pro }}\right)$ with another element like hydraulic element $\left(\mathrm{B}_{\mathrm{Pro}}\right)$. This solution allows eliminating the entanglement risk through rotating element.

- The second solution (b): use guards to cover the rotating elements or they propose protective devices to shut the PTO drive shaft systems down once the operator is in the hazardous zone. 
- The third solution (c): replace the $\mathrm{B}_{\text {Ser }}$ with another $\mathrm{B}_{\text {Ser }}$. Here, $\mathrm{B}_{\text {Ser }}$ is related to performing an activity by person on or around the PTO drive shaft. In this case, $\mathrm{B}_{\text {Ser }}$ cannot be modified.

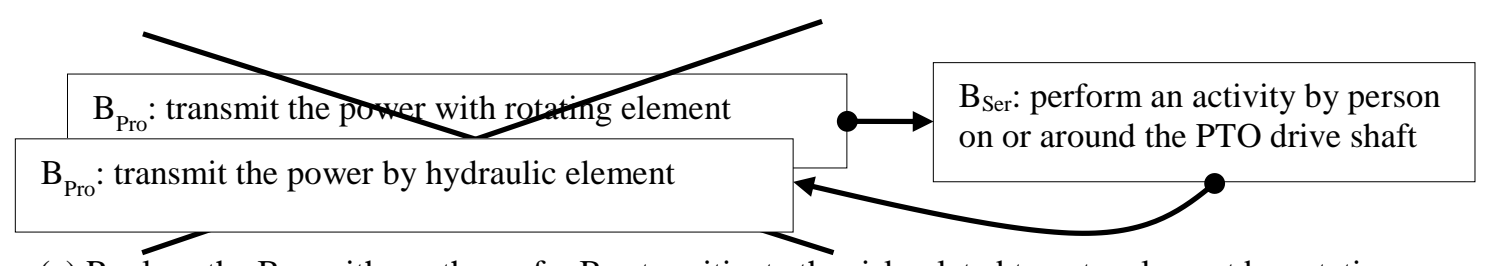

(a) Replace the $\mathrm{B}_{\text {Pro }}$ with another safer $\mathrm{B}_{\text {Pro }}$ to mitigate the risk related to entanglement by rotating element

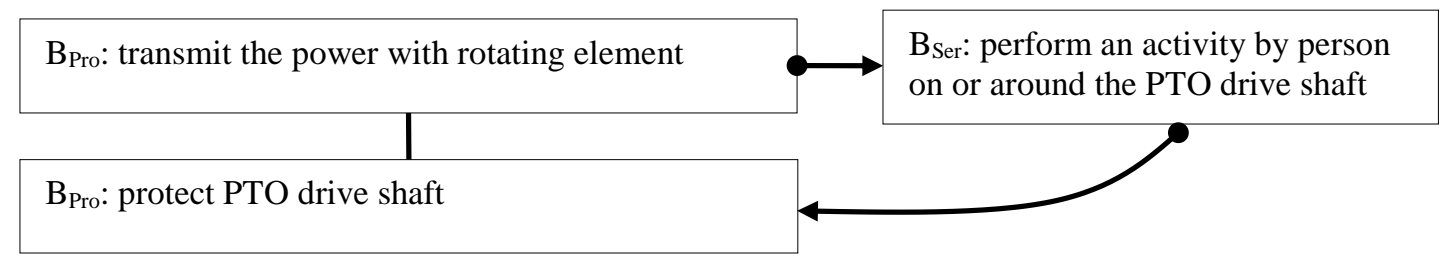

(b) Add another $\mathrm{B}_{\text {Pro }}$ to mitigate the risk related to entanglement by rotating element

$\mathrm{B}_{\text {Pro }}:$ transmit the power with rotating element

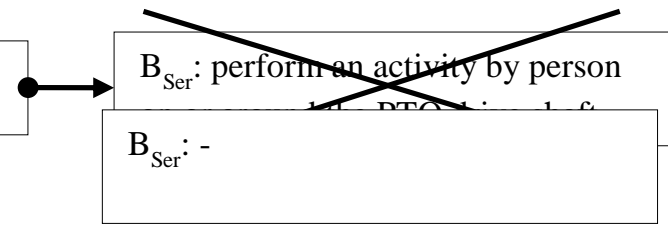

(c) Replace the $\mathrm{B}_{\mathrm{Ser}}$ with another $\mathrm{B}_{\mathrm{Ser}}$ to mitigate the risk related to entanglement by rotating element

Figure 13. Mitigation the risk related to entanglement with rotating element

The CTOC-PTC diagrams for solutions (a) and (b) have been shown in Figure

14. For solution (a), tractor mechanical energy should be converted to hydraulic energy and then hydraulic energy should be transmitted. Hydraulic energy should be then converted to mechanical energy. For solution (b), input and output energy are mechanical energy, but "protect" behavior should be added as a control element. 
(a)

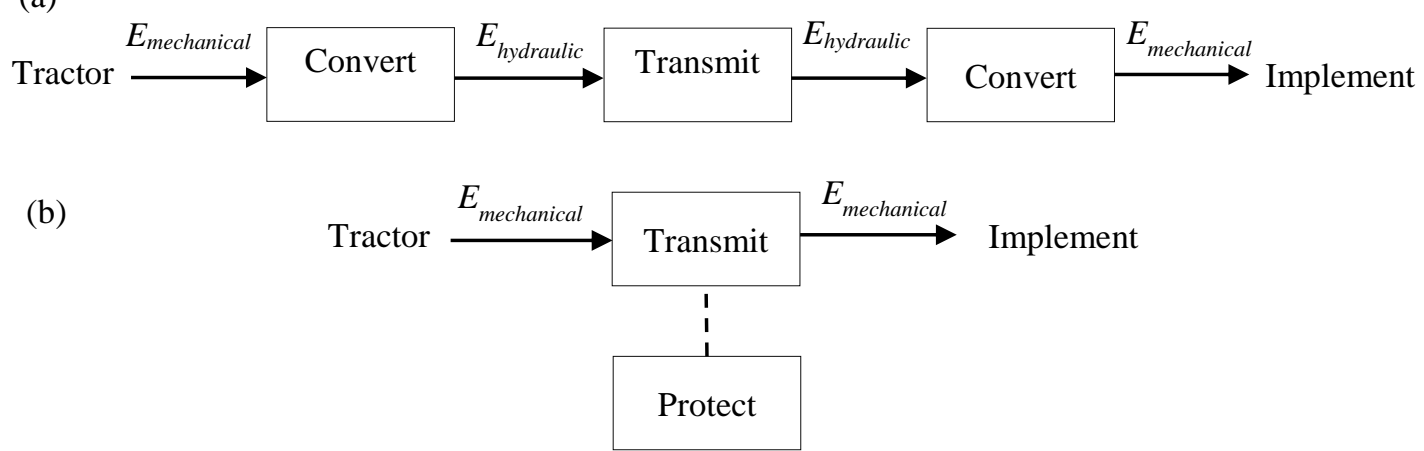

Figure 14. CTOC-PTC diagrams for solutions (a) and (b)

Hydraulic systems have a nasty way of retaining pockets of high pressure. The accident analysis shows, the possibility of injection hazard by these systems. The injection hazard can result in tissue damage, amputation, or at worst, death. An injection injury is caused by a fluid being injected into and under a person's skin at pressure. The pressure fluid results for example from a leaking hydraulic hose or fitting, a split in an air pipe and etc.

These two solutions allow mitigating the entanglement risk with rotating element for transmission mechanical energy connected to the tractor and to the implement. Continuing design process to complete it is not the objectives of this study.

\section{Conclusions}

Although there exist the numerous researches for improve human safety during design process, there still exists a gap between what is imagined in design and what is lived during the product utilization. To overcome this gap, this research proposed to integrate and analysis working situation during design.

As a general conclusion, we are interested in use of Product-Service Systems (PSS) in this research because this research study is looking at the interaction between product and service to identify and analyze the working situation. The proposed approach is based on the Function-Behavior-Structure (FBS) modelling, which covers behavior 
aspect and models this allocation of functions. Regarding the PSS paradigm, we make a distinction between two kinds of behaviors: behaviors of the service part and behaviors of the product part. In other words, the interaction between PSS and FBS allows considering product behaviors $\left(\mathrm{B}_{\mathrm{Pro}}\right)$ and its interaction with service behaviors $\left(\mathrm{B}_{\mathrm{Ser}}\right)$. The analysis of this interaction is helpful for working situation analysis. Indeed, the research novelty of our work lies in that by taking the dynamic service part, it allow to analyse working situation during design. Hence, this study applies to consider any user activity performed in working situation. Product and service behaviors modelling are proposed in order to help this analysis.

This paper argues designing human activities performed in working situation in parallel with products, neither designing only products nor designing human activities. The major characteristic of this research is both product and service are considered from the conceptual design phase. This enables designers to achieve more efficient results on safety improvement in the design process. The applicability of the approach is demonstrated through the application to a Power Take-Off (PTO) drive shaft. For this system, two solutions are listed to mitigate the entanglement risk with rotating element for transmission mechanical energy connected to the tractor and to the implement.

Our proposition allows avoiding risks in the case that risk is known and accidents have occurred in the past. A possible extension for future work is that now that it is possible to identify working situations that have been of risk in the past, would it be possible to predict potential new dangerous working situations induced by the newly designed solutions. This would show that not only you can reduce risks from wellidentified situations but also prevent new risky situations to occur. 


\section{Acknowledgements}

The authors would like to acknowledge the Paris Nouveaux Mondes programme of the heSam University for their financial support.

\section{Reference}

Altshuller, G., 1984. Creativity as an Exact Science. Gordon and Breach Science Publishers, New York, NY.

Altshuller, G., 1999. The Innovation Algorithm. Technical Innovation Center, Worcester, MA.

Aven, T., 2009. Safety is the antonym of risk for some perspectives of risk. Safety Science, 47, pp.925-930. Available at: http://dx.doi.org/10.1016/j.ssci.2008.10.001.

Baines, T.S. et al., 2007. State-of-the-art in product service-systems. Journal of Engineering Manufacture, 221, pp.1543-1552. Available at: http://dx.doi.org/10.1243/09544054JEM858.

Bernard, A. \& Hasan, R., 2002. Working situation model for safety integration during design phase. CIRP Annals - Manufacturing Technology, 51(1), pp.119-122. Available at: http://linkinghub.elsevier.com/retrieve/pii/S0007850607614802.

Braha, D. \& Reich, Y., 2003. Topological structures for modeling engineering design processes. Research in Engineering Design, 14, pp.185-199.

Caputo, A.C., Pelagagge, P.M. \& Salini, P., 2013. AHP-based methodology for selecting safety devices of industrial machinery. Safety Science, 53, pp.202-218. Available at: http://dx.doi.org/10.1016/j.ssci.2012.10.006.

Cook, M.B., Bhamra, T. a. \& Lemon, M., 2006. The transfer and application of Product Service Systems: from academia to UK manufacturing firms. Journal of Cleaner Production, 14, pp.1455-1465.

Duijne, F. van et al., 2007. Design for safety: Involving users' perspectives Redesign proposals for gas lamps using a pierceable cartridge. Safety Science, 45, pp.253281.

European Committee for Standardization (CEN), 2009. Safety of machinery Ergonomic design principles - Part 1: Terminology and general principles. Standard No. NF EN 614-1+A1: 2009.,

European Committee for Standardization (CEN), 2010. Safety of machinery - General principles for design - Risk assessment and risk reduction. Brussels: CENELEC; 2010. Standard No. NF EN ISO 12100:2010, 
Fadier, E. \& De La Garza, C., 2006. Safety design: Towards a new philosophy. Safety Science, 44, pp.55-73.

Finger, S. \& Dixon, J.R., 1989a. A review of research in mechanical engineering design. Part I: Descriptive, prescriptive, and computer-based models of design processes. Research in Engineering Design, 1, pp.51-67.

Finger, S. \& Dixon, J.R., 1989b. A review of research in mechanical engineering design. Part II: Representations, analysis, and design for the life cycle. Research in Engineering Design, 1, pp.121-137.

Gero, J.S., 1990. Design prototypes: A knowledge representation scheme for design. AI Magazine, 11(4), pp.26-36.

Gero, J.S. \& Kannengiesser, U., 2004. The situated function-behavior-structure framework. Design Studies, 25, pp.373-391.

Ghemraoui, R., Mathieu, L. \& Tricot, N., 2009. Design method for systematic safety integration. CIRP Annals - Manufacturing Technology, 58, pp.161-164.

Hasan, R., 2002. Contribution à l'amélioration des performances des systèmes complexes par la prise en compte des aspects socio-techniques dès la conception : proposition d'un modèle original de situation de travail pour une nouvelle approche de conception. 'Université Henri Poincaré, Nancy I. Available at: http://hdl.handle.net/2332/1819.

Hatchuel, A. \& Weil, B., 2003. a New Approach of Innovative Design : an Introduction To C-K Theory. International Conference on Engineering Design, pp.1-15.

Hollnagel, E., 2008. Risk + barriers = safety? Safety Science, 46, pp.221-229.

Houssin, R. et al., 2006. Information system based on a working situation model for a new design approach in concurrent engineering. Journal of Engineering Design, 17(1), pp.35-54. Available at: http://www.tandfonline.com/doi/abs/10.1080/09544820500276048 [Accessed March 22, 2013].

Houssin, R. \& Coulibaly, A., 2011. An approach to solve contradiction problems for the safety integration in innovative design process. Computers in Industry, 62(4), pp.398-406. Available at: http://linkinghub.elsevier.com/retrieve/pii/S0166361510001818 [Accessed March 22, 2013].

Houssin, R., Sun, H. \& Gardoni, M., 2010. A Behavioral Design Approach to Improving Mechanical System Design with Integration of Use Conditions. International Journal of Design and Innovation Research, 5(3), pp.1-24.

Johnson, C. \& Holloway, C.M., 2003. A survey of logic formalisms to support mishap analysis. Reliability Engineering \& System Safety, 80, pp.271-291. 
Kannengiesser, U. \& Gero, J.S., 2011. A Framework for Constructive Design Rationale. , pp.1-20.

Khan, F. \& Abbasi, S., 1998. Inherently safer design based on rapid risk analysis. Journal of Loss Prevention in the Process Industries, 11, pp.361-372.

Licht, D.M., Polzella, D.J. \& Boff, K.R., 2005. Human Factors, Ergonomics, and Human Factors Engineering: An Analysis of Definitions. Harry G. Armstrong Aerospace Medical Research Laboratory, U.S.A, (513).

Lo, S. \& Helander, M.G., 2007. Use of axiomatic design principles for analysing the complexity of human-machine systems. Theoretical Issues in Ergonomics Science, 8(2), pp.147-169.

Lossack, R. \& Grabowski, H., 2000. the Axiomatic Approach in the Universal Design Theory. In Proceedings of the 1th International Conference on Axiomatic Design, ICAD 2000.

Manzini, E. \& Vezzoli, C., 2003. A strategic design approach to develop sustainable product service systems: Examples taken from the "environmentally friendly innovation” Italian prize. Journal of Cleaner Production, 11, pp.851-857.

Le Masson, P. \& Weil, B., 2013. Design theories as languages of the unknown: Insights from the German roots of systematic design (1840-1960). Research in Engineering Design, 24, pp.105-126.

MIL-STD-882D, 2000. Standard practic for system safety, Available at: US Department of Defense, Washington, DC.

Pahl, G. et al., 2007. Engineering Design A Systematic Approach, Springer-Verlag London Limited.

Reich, Y., 1995. Engineering Design A Critical Review of General Design Theory Yoram Reich. Research in Engineering Design, 7, pp.1-18.

Reniers, G. et al., 2005. Developing an external domino accident prevention framework: Hazwim. Journal of Loss Prevention in the Process Industries, 18, pp.127-138.

Sadeghi, L. et al., 2015. Developing a safety indicator to measure the safety level during design for safety. Safety Science, 80, pp.252-263. Available at: http://linkinghub.elsevier.com/retrieve/pii/S092575351500209X.

Sadeghi, L. et al., 2013. Toward design for safety Part 1 : Functional reverse engineering driven by axiomatic design. In Proceedings of the 7th International Conference on Axiomatic Design, ICAD 2013.

Shahrokhi, M., 2006. Intégration d'un modèle de situation de travail pour l'aide à la formation et à la simulation lors de la conception et l'industrialisation de systèmes. Ecole Centrale de Nantes. 
Suh, N.P., 2001. Axiomatic Design: Advances and Applications New York: Oxford University Press, ed.,

Suh, N.P., 1990. The Principles of Design, Oxford University Press, New York, NY.

Sun, H. et al., 2013. Integration of user behavior and product behavior during the design phase: Software for behavioral design approach. International Journal of Industrial Ergonomics, 43(1), pp.100-114. Available at: http://dx.doi.org/10.1016/j.ergon.2012.11.009.

Sundin, E., Lindahl, M. \& Ijomah, W., 2009. Product design for product/service systems: Design experiences from Swedish industry. Journal of Manufacturing Technology Management, (20), pp.723-753. Available at: http://dx.doi.org/10.1108/17410380910961073.

Tomiyama, T., 1997. A manufacturing paradigm toward the 21 st century. Integrated Computer-Aided Engineering, 4, pp.159-178. Available at: http://www.scopus.com/inward/record.url?eid=2-s2.00030680039\&partnerID=40\&md5=e89c6a5c0ab2e0f8a6a90a258008f238.

Tomiyama, T. et al., 2009. Design methodologies: Industrial and educational applications. CIRP Annals - Manufacturing Technology, 58, pp.543-565.

Umeda, Y. et al., 1990. Function, behavior, and structure. Applications of Artificial Intelligence in Engineering V, 1, pp.177-193. Available at:

http://diyhpl.us/ bryan/papers2/Function, behavior, and structure - Umeda 1984.pdf.

Umeda, Y., Nonomura, A. \& Tomiyama, T., 2000. Study on life-cycle design for the post mass production paradigm. Artificial intelligence for engineering design analysis and manufacturing, 14, pp.149-161.

Vasantha, G.V.A. et al., 2012. A review of product-service systems design methodologies. Journal of Engineering Design, 23, pp.635-659.

Weber, C., 2005. CPM/PDD - An Extended Theoretical Approach to Modelling Products and Product development Processes. In H. Bley et al., eds. Proceedings of the 2nd German-Israeli Symposium on Advances in Methods and Systems for Development of Products and Processes. Stuttgart, Germany, pp. 159-179.

Willquist, P. \& Törner, M., 2003. Identifying and analysing hazards in manufacturing industry - A review of selected methods and development of a framework for method applicability. International Journal of Industrial Ergonomics, 32, pp.165180.

Yang, X. et al., 2009. A practical methodology for realizing product service systems for consumer products. Computers and Industrial Engineering, 56, pp.224-235. 
